\title{
Research on the Bilingual Education Reform in Control Techniques
}

\author{
Yan Huo ${ }^{1}$, Yajun Ren², Li Feng ${ }^{1}$, Guangying Yang ${ }^{1, a}$ \\ ${ }^{1}$ College of Information Engineering, Shenyang University, Shenyang 110044, China \\ 2Department of Automatic control, Liaoning Equipment Manufacturing Professional Technology \\ Institute, Shenyang 110160, China \\ axxxyjwb@163.com
}

\begin{abstract}
For the new characteristics of the development of control techniques, bilingual education is improved for creating good learning environment aspects and promoting students' professional level. This paper summarizes and discusses bilingual education aspects in professional courses about control techniques, including teaching mode, learning method, teaching material selection, international level and learning assessment. The research of bilingual education can provide a reference for building an education structure of advanced technology application and strengthening students' international communication ability.
\end{abstract}

Keywords: Bilingual education, control techniques, international communication, teaching mode, learning method.

\section{Introduction}

To adapt to the trend of higher education internationalization, bilingual education needs to be carried out and developed [1]. Industry 4.0 [2] promotes the development of industrial economy, and also propels the reform of high engineering education. Now controlling engineering talents with internationalization capability are urgently needed. Therefore, it is important that bilingual education is introduced into the education field of control techniques. The bilingual education of control techniques can cultivate and improve students' comprehensive ability in control engineering participating in international cooperation and communication. Meanwhile, it can exercise the students' English listening speaking and writing ability.

\section{Significance of Bilingual Education Reform}

Control techniques in the hot field change and update very quickly. The new development of global control techniques is often reported in English. In order to obtain the latest knowledge for the courses, we must acquire the skills of English expression and reading. Bilingual learning allows students to get the new technology development. Moreover, English as the most popular language, bilingual education can exercise the students' ability of international communication and cultivate students' innovative thinking. Due to the fierce competition of talent market, the demand of technological companies becomes higher than before [3]. The ability of independent learning for new skills and high level for English will improve the graduates' competition for employment. The internationalization of teaching activities is of great significance for the cultivation of professional technical personnel. Therefore, the implementation of bilingual education is necessity and urgency for control techniques.

\section{Current Situation of Bilingual Education}

There are some problems for traditional bilingual education. Firstly, several students' English language ability for professional words of control techniques is relatively weak. Through teaching experiments of control techniques, it is found that the English levels of students are uneven in using professional English. Secondly, it is difficulty to select the teaching materials about the bilingual education of control techniques. Most of them are academic, lacking the introduction of the basic 
knowledge in control techniques. So, it can bring some difficulties to the bilingual classes of control techniques for teachers and students. Final examination is another disputed problem. The formats and the content of some exams are still unclear. Some current bilingual exams focus mainly on English vocabularies. Then there could be the loss of examination significance. The questions of the traditional examinations are very rigid, which cannot reflect the training requirements for students' ability. The examination content is simplex so that some students can pass after a short learning time. In addition, higher requirements have been put forward for teachers in bilingual education. The teachers need to not only learn the professional English but also obtain the advanced information about control techniques.

Recently bilingual education of control techniques has been improved for teaching quality. The bilingual education of control techniques has been paid attention more and more. It is clear that more and more university students begin to be interested in involving into international learning of professional skills and obtain updated sciences and technologies.

\section{Improvement Tactics of Bilingual Education}

In order to improve the effect of bilingual education of control techniques further, some exploratory factors on teaching mode, learning method, teaching material selection, international communication level and teaching assessment are discussed as Fig.1.

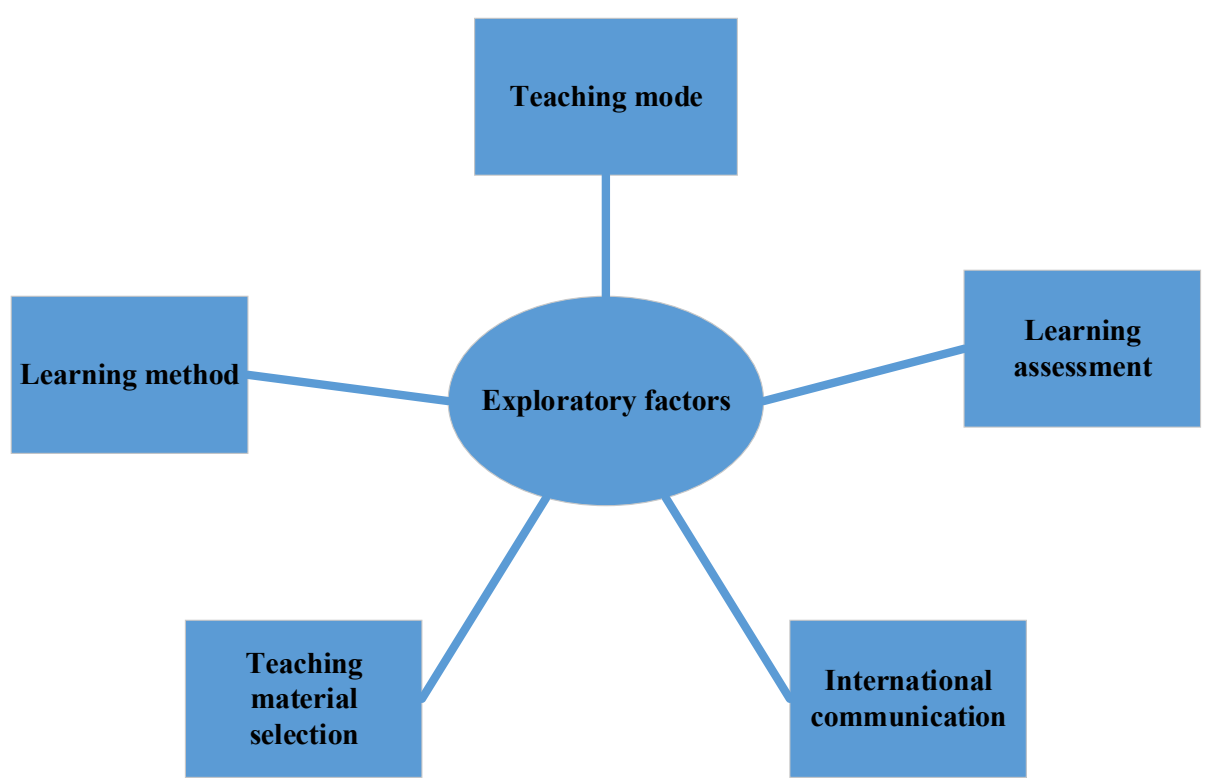

Fig. 1 Exploratory factors for bilingual education of control techniques

\subsection{Teaching Mode}

Teaching mode should be improved to meet the requirements of bilingual education in control techniques. According to the characteristics of control techniques, teaching mode should be more open and flexible, being different from the traditional teaching mode. So many teaching ideas can be combined into the teaching mode to enhance teaching efficiency. The teachers should have open mind to learn and construct the education mode. The students can be also involved in the construction of some courses.

Based on the engineering application of control techniques, it is necessary to focus on the new information theories and new control methods for teachers and students. The objective of the teaching mode is also to combine control theory with engineering application for training the students' ability to solve application problems. In this process, capital investment should be increased to strengthen the construction of control technique infrastructure and enlarge bilingual teaching activities.

With the development of teaching mode, teaching methods need to keep real-time revision, especially combining the current progress of international advanced data and course content. For 
example, by configuring the application experiments, the courseware should be lively and interesting, and some videos can be used to record and show some real engineering processes and technology realization details to stimulate students' interest. Moreover, bilingual teaching cannot be confined to foreign language teaching. Students must master the knowledge of the subject firstly. It is a false thing to reduce the teaching quality for meeting bilingual education format. So a two-step method is used to solve the problem. Before teaching professional knowledge, the first step is to teach or allow students to learn the English professional vocabularies and certain impossible difficulties in Chinese for this following chapter of the course. The second step is to teach the main content, including algorithms, application skills and key thoughts for students in English. At the beginning of each class, teachers can provide the teaching content of the first step for students to review to make this course smoothly.

So, students can complete the in-depth study for this course. In addition, the blackboard writing in class can be completely expressed in English. It is noted that teachers should explain the key knowledge points in Chinese, so that students could accept them fully and completely.

\subsection{Learning Method}

Learning method is important for students and teachers. Students' active learning affects the results of bilingual education in some extent. Therefore, for overcoming the problems of professional knowledge students should arise their enthusiasm for bilingual learning gradually. The students should realize the importance of the bilingual courses, which can enhance their competence of future talents market. The students should prepare the following lessons and go over what they have learnt. They should also participate in some activities about English learning or technical exchange in their spare time. The students are encouraged to consult and discuss their classmates and professors with some topics of control techniques. Students should actively participate in the international college innovation design competition. The topics of the competition are determined by themselves.

\subsection{Teaching Material Selection}

Bilingual education content should meet the development and innovation of science and technology. It is clear that the goal of bilingual teaching about control techniques is not stick to the traditional teaching with routine teaching materials. The material selection should adapt to the open teaching content accordance with school characteristics. It is suggested that English teaching materials are provided as the main curriculum content in class, and Chinese teaching materials could be considered as auditory aids to be used for students' autonomous query and learning.

In view of the educational reform of control techniques, teachers' courseware are also important to provide the teaching content of control techniques. They are integrated with a variety of media, with the combination of three-dimensional teaching materials. The bilingual courseware cannot be directly translated from Chinese courseware and cannot be completely copied from English materials. The bilingual courseware should not only cover knowledge points of teaching techniques, but also stimulate students' interest in learning the professional skills.

\subsection{International Communication}

International communication is a necessary part in bilingual education of control techniques. By international communication, the latest development of control techniques is obtained. Many ways of international communication can be selected. The teachers and students are encouraged to attend some relevant international meetings and seminars. And some teachers and students are always sent to study aboard. Recently the social media platform based on Internet becomes popular. It is a communication tool for sharing opinions and experiences. Internet communication is very convenient to get the overseas information. The teachers aboard can use webcast to teach the lessons of control techniques. The online teaching makes up for the traditional teaching deficiency in time and space limitations. The online teaching can complete the real-time interaction between teachers and students. So, by making use of the advantages of Internet technology, the students' ability of communication with an international perspective can be improved. 


\subsection{Learning Assessment}

Learning assessment of control techniques for bilingual education also faces new challenges. Examination as a popular method is used to assess the learning outcome. The assessment content not only should show the technique content of teaching, but also should reflect the features of bilingual teaching. The test methods are designed to promote the learning interest and reflect the knowledge mastering of the course clearly. The student grade for a course consists two parts, including one part $(30 \%)$ from the class debate and discussion or the summary paper, the other part $(70 \%)$ from the final exam. Increasing the proportion of applied questions in the examination can focus on the assessment of students' ability to solve with practical engineering problems by using learned knowledge. The final exam should be provided in English. Students can answer the questions of the final examination in Chinese or English. But the class discussion and the summary paper are encouraged in English. Then the test method can test the students' knowledge level and release the students' lesson burden.

\section{Summary}

Bilingual education reform of control techniques has been explored and discussed in many universities. The teaching reform methods should be adjusted according to the university situation. The course process of bilingual education about control techniques not only can achieve the teaching objectives, but also can ensure the teaching quality. The implementation effect is analyzed regularly, and the mode of the curriculum would be improved according to the analysis results. It is also important that the education reform will meet the social need and students' characteristics to further improve the teaching efficiency.

\section{References}

[1]. Tan D. Bilingual Education: Strategy selection of internationalization of higher education in China. Educational Research, Vol. 394(2012), 11: p6068-6071.

[2]. Paravizo E, Chaim O C, Braatz D, et al. Exploring gamification to support manufacturing education on industry 4.0 as an enabler for innovation and sustainability. Procedia Manufacturing, Vol. 21 (2018), p438-445.

[3]. Zhi Z. Practical reform of bilingual education in control techniques of robots. Computer Education, (2010), 19: p125-127.

[4]. Leung C. Language and content in bilingual education. Linguistics and Education, 16(2005), 2 : p238-252. 